OPEN ACCESS

Edited by:

Frederico Marianetti Soriani, Federal University of Minas Gerais,

Brazil

Reviewed by:

Michelle Amantea Sugimoto,

University College London,

United Kingdom

Daiane Boff,

New York University, United States

*Correspondence:

Metiner Tosun

metiner.tosun@ieu.edu.tr

Specialty section:

This article was submitted to

Molecular Diagnostics and

Therapeutics,

a section of the journal

Frontiers in Molecular Biosciences

Received: 07 June 2021 Accepted: 07 September 2021

Published: 12 October 2021

Citation:

Baris E, Efe H, Gumustekin M, Arici MA and Tosun M (2021) Varenicline Prevents LPS-Induced Inflammatory Response via Nicotinic Acetylcholine

Receptors in RAW

264.7 Macrophages.

Front. Mol. Biosci. 8:721533.

doi: 10.3389/fmolb.2021.721533

\section{Varenicline Prevents LPS-Induced Inflammatory Response via Nicotinic Acetylcholine Receptors in RAW 264.7 Macrophages}

\author{
Elif Baris ${ }^{1,2}$, Hande Efe ${ }^{3}$, Mukaddes Gumustekin ${ }^{4}$, Mualla Aylin Arici ${ }^{4}$ and Metiner Tosun ${ }^{2 *}$ \\ ${ }^{1}$ Department of Pharmacology, Graduate School of Health Sciences, Dokuz Eylul University, Izmir, Turkey, ${ }^{2}$ Department of \\ Pharmacology, Faculty of Medicine, Izmir University of Economics, Izmir, Turkey, ${ }^{3}$ Department of Medical Biology and Genetics, \\ Graduate School of Health Sciences, Dokuz Eylul University, Izmir, Turkey, ${ }^{4}$ Department of Medical Pharmacology, Faculty of \\ Medicine, Dokuz Eylul University, Izmir, Turkey
}

The cholinergic anti-inflammatory pathway plays an important role in controlling inflammation. This study investigated the effects of varenicline, an a7 nicotinic acetylcholine receptor ( $\mathrm{a} 7 \mathrm{nAChR}$ ) agonist, on inflammatory cytokine levels, cell proliferation, and migration rates in a lipopolysaccharide (LPS)-induced inflammation model in RAW 264.7 murine macrophage cell lines. The cells were treated with increasing concentrations of varenicline, followed by LPS incubation for $24 \mathrm{~h}$. Prior to receptor-mediated events, anti-inflammatory effects of varenicline on different cytokines and chemokines were investigated using a cytokine array. Nicotinic AChR-mediated effects of varenicline were investigated by using a non-selective nAChR antagonist mecamylamine hydrochloride and a selective a7nAChR antagonist methyllycaconitine citrate. TNF $\alpha$, IL-1 $\beta$, and IL-6 levels were determined by the ELISA test in cell media $24 \mathrm{~h}$ after LPS administration and compared with those of dexamethasone. The rates of cellular proliferation and migration were monitored for $24 \mathrm{~h}$ after drug treatment using a real-time cell analysis system. Varenicline decreased LPS-induced cytokines and chemokines including TNF $\alpha, I L-6$, and IL-1 $\beta$ via $\alpha 7 n A C h R s$ to a similar level that observed with dexamethasone. Varenicline treatment decreased LPS-induced cell proliferation, without any nAChR involvement. On the other hand, the LPS-induced cell migration rate decreased with varenicline via $\alpha 7 \mathrm{nAChR}$. Our data suggest that varenicline inhibits LPS-induced inflammatory response by activating $a 7 n A C h R s$ within the cholinergic antiinflammatory pathway, reducing the cytokine levels and cell migration.

Keywords: varenicline, $\alpha 7 \mathrm{nAChR}$, inflammation, cytokine, proliferation, migration

\section{INTRODUCTION}

Lipopolysaccharide (LPS), an endotoxin of Gram-negative bacteria, induces "pathogen-associated molecular pattern (PAMP) recognition receptors" (toll-like receptors, TLRs expressed on immune system cells. Exposure to LPS initiates an inflammatory response that includes unrestrained production of pro-inflammatory cytokines: tumor necrosis factor (TNF), interleukins (IL-1, IL-6, and IL-8), and platelet-activating factor (PAF) from immune cells (Palsson-McDermott and O'Neill, 2004; Murdock and Núñez, 2016). 
Uncontrolled pro-inflammatory cytokine release initiates systemic inflammatory response that can be regulated by the cholinergic system, which is crucial for balancing the body's response to inflammation and survival. The control of inflammation through the parasympathetic system is called the cholinergic anti-inflammatory pathway (CAP). The CAP is defined as a comprehensive neural mechanism that attenuates pro-inflammatory cytokine release through the vagus nerve and activation of nicotinic receptors expressed on mononuclear phagocytic cells such as lymphocytes, macrophages, mast cells, dendritic cells, basophils, and microglia (Fujii et al., 2017; Snider et al., 2018). The pharmacological activation of cholinergic receptors or electrical stimulation of the vagus nerve limits pro-inflammatory cytokine production in various models (i.e., ischemia, pancreatitis, colitis, hemorrhage, and sepsis). Clinical studies showed that agents acting on the cholinergic anti-inflammatory pathway improved sequential organ failure and mortality rates in patients with sepsis (Zimmermann et al., 2017; Pinder et al., 2019a; Pinder et al., 2019b). Most of the studies have focused on pharmacological interventions to activate cholinergic receptors, particularly $\alpha 7 \mathrm{nAChR}$, and their expression on immune cells is required for communication between the cholinergic system and the immune system cells. The inhibitory effect of $a 7 n A C h R$ agonists on TNFa, IL-1, IL-6, and IL-8 plays an important anti-inflammatory role. Studies showed that $a 7 \mathrm{nAChR}$ agonists, such as nicotine, acetylcholine, choline, or GTS-21 modulate LPS-induced proinflammatory cytokines, promote and improve survival in different experimental models (Borovikova et al., 2000; Pavlov et al., 2007; Fujii et al., 2017; Zimmermann et al., 2017; Snider et al., 2018). Thus, $\alpha 7 n$ AChR-activating agents appear to have therapeutic efficacy in inflammatory processes (Borovikova et al., 2000; Bernik et al., 2002; De Jonge and Ulloa, 2007; Zimmermann et al., 2017; Pinder et al., 2019a; Pinder et al., 2019b).

Following LPS-induced TLR activation, macrophages migrate into inflamed tissues and eliminate pathogens via phagocytosis. LPS-activated macrophages produce different cytokines and chemokines including macrophage inflammatory proteins, monocyte chemoattractant proteins, TNFa, IL-1 $\beta$, and IL-6, which in turn stimulate macrophage migration (Toh et al., 2006; Yang et al., 2015). On the other hand, acetylcholine reportedly inhibits LPS-induced matrix metalloproteinase 9 (MMP-9) production and macrophage migration via a7nAChR activation (Yang et al., 2015).

Widely used as an efficient and safe therapeutic option for smoking cessation, varenicline reportedly has potent and full agonistic properties on $a 7 \mathrm{nAChRs}$, besides having partial agonistic effects on $\alpha 4 \beta 2-n A C h R s$ (Mihalak et al., 2006a; 2006b; Hays et al., 2008). A recent clinical study has demonstrated that 12-week varenicline treatment modulates inflammation and oxidative damage (McElroy et al., 2018). Furthermore, immunohistochemical experiments have shown that varenicline treatment suppressed inflammation and the number of immune system cells, via $\alpha 7 \mathrm{nAChR}$ activation in the brain and lung tissues in an animal model of ischemia and emphysema (Chen et al., 2017; Koga et al., 2018). However, there is no clear explanation on the role of varenicline in LPS-induced inflammatory response and macrophage migration. Therefore, this study investigated the effects of varenicline on a $\mathrm{nAChR}$-mediated activation of CAP, cell proliferation, and migration induced by LPS.

\section{MATERIAL AND METHODS}

\section{Cell Culture}

RAW 264.7 murine macrophage cells (ATCC TIB-71, Manassas, VA, United States) were maintained in DMEM (Sigma Aldrich D6429), supplemented with heat-inactivated FBS (10\%) and penicillin $(100 \mathrm{U} / \mathrm{ml})$ and streptomycin $(100 \mu \mathrm{g} / \mathrm{ml}$, Gibco, Carlsbad, $\mathrm{CA}$ ) at $37^{\circ} \mathrm{C}$ in a $5 \% \mathrm{CO}_{2}$ incubator. Regular checks for Mycoplasma contamination were performed with a mycoplasma detection kit (Biowest, Riverside, MO, United States). The cells (500,000/well) were seeded in 48-well tissue culture plates after detachment with scraping incubated for $24 \mathrm{~h}$ in serum-free media for reattachment to the surface. Before adding chemicals, the medium was replaced with fresh serum-free media. In the first group, the cells were treated with LPS (Escherichia coli, Sigma-Aldrich L4130 0111: B4) at various concentrations (in $\mu \mathrm{g} / \mathrm{ml}: 0.5-2.5-4$ and 5) to determine the effective concentration at which cytokines are released (Parrish et al., 2008). In the second group, the cells were pretreated with varenicline tartrate (SigmaAldrich PZ0004) with increasing concentrations (in $\mu \mathrm{M}$ : 1-3-10-30) $30 \mathrm{~min}$ prior to LPS administration to determine effective varenicline concentration on LPS-induced cytokine levels. Additionally, the anti-inflammatory effect of varenicline was compared with that of dexamethasone $(0.1 \mu \mathrm{M}$, Sigma-Aldrich D4902) (Ai et al., 2020). In the third group, to investigate the involvement of nicotinic receptors, a non-selective nicotinic ACh receptor antagonist mecamylamine hydrochloride (MEC, $50 \mu \mathrm{M}$, Sigma-Aldrich M9020) and a selective $a 7 \mathrm{nAChR}$ antagonist methyllycaconitine citrate (MLA, $1 \mu \mathrm{M}$, Sigma-Aldrich M168) were applied $30 \mathrm{~min}$ before varenicline and LPS administration (Yang et al., 2015; Yi et al., 2015). RAW 264.7 cells at passage \#5 were originally obtained from ATTC (gift).

\section{Protein Analyses}

The levels of TNFa, IL-1 $\beta$, and IL- 6 released into the culture media $24 \mathrm{~h}$ after LPS administration were determined by the enzyme-linked immunosorbent assay (ELISA) (Invitrogen, Carlsbad, CA) and cytokine array (Proteome Profiler ${ }^{\mathrm{TM}}$ Array, Panel A, R, and D System, Minneapolis, MN, United States) according to the manufacturer's instructions.

\section{Proliferation and Migration Assays}

A real-time cell analysis system (xCELLigence RTCA DP "dual purpose," Acea Biosciences, San Diego) was used to monitor proliferation or migration in real time in different plates and experimental settings. E-plate 16, used for proliferation assay, is a single-use cell culture plate with highly sensitive gold microelectrodes. Real-time changes in electrical impedance were expressed as cell index (CI).The background impedance of $100 \mu \mathrm{L}$ medium was measured prior to seeding cells $(10,000$ cells/well). The cells were incubated at room temperature for $30 \mathrm{~min}$ before running RTCA. After 24-h 


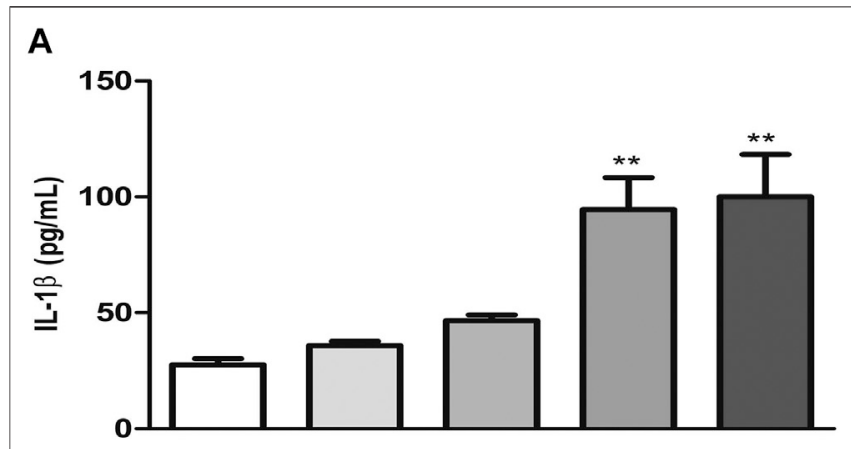

B

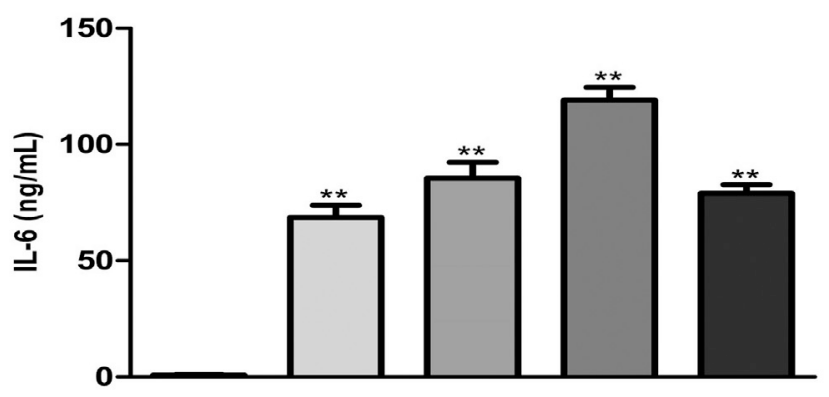

C

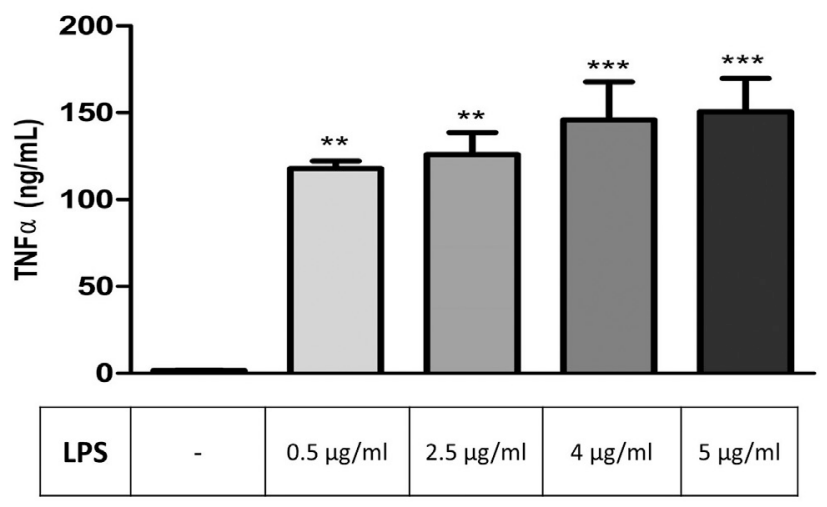

FIGURE 1 | LPS-induced increase in inflammation markers in RAW264.7 cells. Shown are IL-1 $\beta$ (A); IL-6 (B), TNF $\alpha$ (C) levels in response to increasing LPS concentrations. Data are expressed as mean \pm S.E.M. ${ }^{* \star} p<$ $0.01 ;{ }^{\star \star \star} p<0.001$ vs. the control group, $n=5-7$, One-way ANOVA with post hoc Tukey-Kramer multiple comparisons test or Student's $t$-test).

proliferation, cells were treated with LPS $(4 \mu \mathrm{g} / \mathrm{ml})$ with or without varenicline $(1 \mu \mathrm{M})$. The change in cell proliferation was monitored for $48 \mathrm{~h}$ at 15 -min intervals. Negative control groups (cell-free culture medium) were tested in each plate.

The migration assay was also performed using the xCELLigence RTCA DP instrument, which allows us to monitor cell invasion and migration (CIM) through the inner microporous membrane assembled within an integrated Boyden chamber. As in the proliferation assay, real-time changes in electrical impedance were also recorded. Before the experiments, the cells were washed with a serum-free medium $24 \mathrm{~h}$ before the experiment and then seeded (30,000 cells/well) in the upper migration chamber (CIM plate) with the serum-free medium and incubated at room temperature for $30 \mathrm{~min}$. The lower chambers were filled with a serum-containing medium, and the upper chambers with serum-free medium. The number of cells migrated from the upper to the lower chamber was determined real time for $24 \mathrm{~h}$ with 15-min intervals after drug treatment. The change in the cell migration rate was expressed as cell index (CI) (Bird and Kirstein, 2009; Cano et al., 2016; Selli et al., 2016).

In the first migration assay group, the cells were treated with LPS $(4 \mu \mathrm{g} / \mathrm{ml})$ in the presence or absence of varenicline $(1 \mu \mathrm{M})$. The second group was treated with a non-selective $n A C h R$ antagonist MEC $(50 \mu \mathrm{M})$ and/or a selective $a 7 \mathrm{nAChR}$ antagonist MLA $(1 \mu \mathrm{M})$, both of which were applied $30 \mathrm{~min}$ before varenicline and LPS administration. The change in the cell migration rate was monitored for $48 \mathrm{~h}$ at 15 -min intervals. Negative control groups (serum- and cell-free culture medium) were tested in each plate, as reported previously (Bird and Kirstein, 2009; Cano et al., 2016).

\section{Statistical Analysis}

One-way analysis of variance analysis (ANOVA) with post hoc Tukey-Kramer multiple comparison tests or Student's $t$-test (GraphPad Prism 5, La Jolla, CA) were used to compare means. Data were expressed as mean \pm S.E.M $(n=5-7$, each performed in triplicate), and a $p$ value $<0.05$ was accepted as statistically significant.

\section{RESULTS}

\section{Inhibitory Effects of Varenicline on LPS-Induced Cytokine Secretions From Macrophages}

RAW 264.7 cells were exposed to increasing concentrations of LPS $(0.5,2.5,4$, and $5 \mu \mathrm{g} / \mathrm{ml})$ for $24 \mathrm{~h}$ before analyzing IL- $1 \beta$, IL6 , and TNFa levels to determine the effective concentration of LPS to be used in other groups of experiments. All three parameters increased significantly depending on LPS concentration in comparison to controls, and the maximum effective concentration of LPS, which induces the secretion of all three cytokines, was found to be $4 \mu \mathrm{g} / \mathrm{ml}$ (Figures 1A-C).

In the second set of experiments, RAW 264.7 cells were treated with varenicline $(1 \mu \mathrm{M})$ prior to the incubation with LPS $(4 \mu \mathrm{g} / \mathrm{ml})$ for $24 \mathrm{~h}$. Cytokine array was performed to monitor 40 different cytokines released from the same cell populations used in experimental protocols in order to find the target inflammatory cytokines whose levels were affected by LPS and varenicline administration. Cytokine array showed that LPS elevated at least 14 out of 40 cytokines, including macrophage inflammatory proteins (MIP-1 $\alpha$, the MIP$1 \beta$, and MIP-2), IL-1, IL-6, IL-27, TNFa, RANTES (regulated upon activation and normal T-cell expressed and secreted, also known as chemokine C-C motif ligand 5, CCL5), interferon gamma-induced protein 10 (IP-10), and monocyte chemoattractant protein (MCP-1 or JE) compared to the control group (Figures $2 \mathrm{~A}, \mathbf{B}$ ). Varenicline decreased LPS-induced levels of these cytokines compared to the LPS group (each dot is in duplicate and represents 5-7 samples, pooled data, Figures $2 \mathrm{~A}-\mathrm{C}$ ). 
A

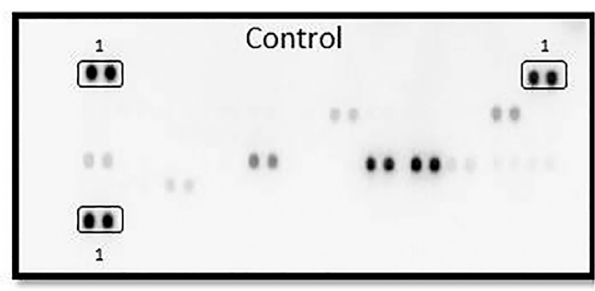

B

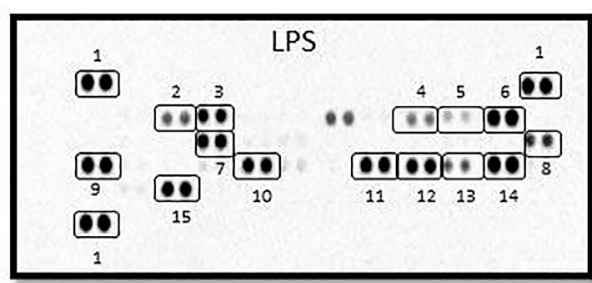

C

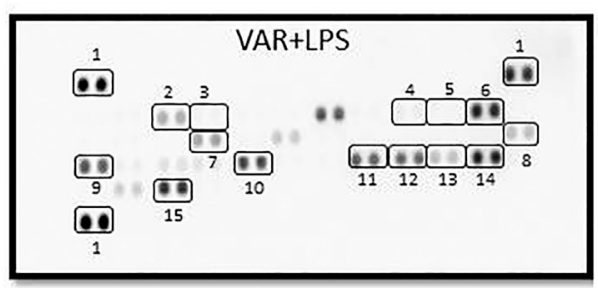

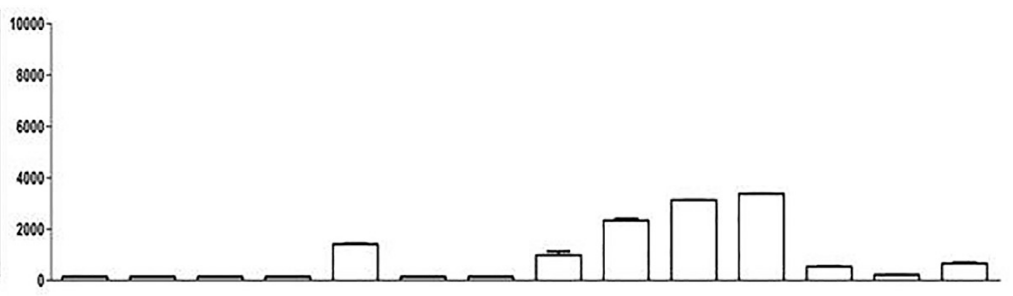
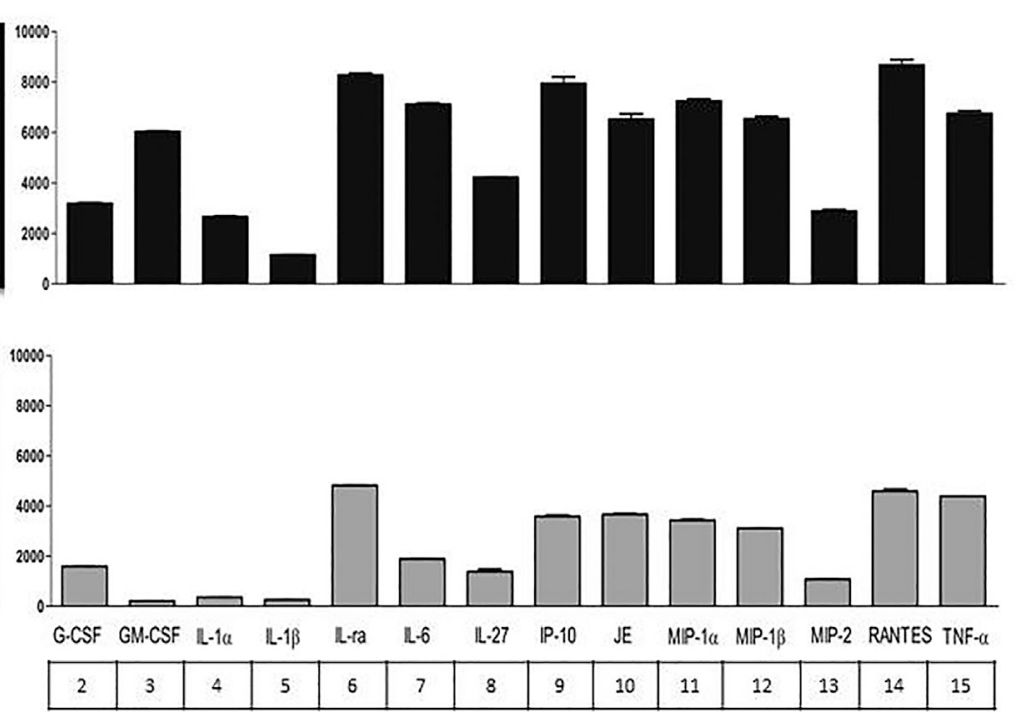

FIGURE 2 | Effects of varenicline on LPS-induced cytokine levels in RAW 264.7 macrophages. Shown are membrane-based antibody arrays of 14 mouse cytokines found in supernatants of the control group (A), $4 \mu \mathrm{g} / \mathrm{ml}$ LPS-induced (B) and LPS-induced macrophages in the presence of $1 \mu \mathrm{M}$ varenicline (VAR) (C). Each sample dot corresponds to a specific cytokine released from the same cell population used in other experiments (pooled data, $n=5-7$ ). Bar graphics show averaged pixel intensities of each dot in duplicate. The table below the right panel shows the numerical annotations of the relevant cytokines detected in the left membranes (1: reference spot).

\section{Inhibitory Effects of Varenicline on LPS-Induced IL-1 $\beta$, IL-6, and TNF $\alpha$ Elevations Determined by ELISA}

RAW 264.7 cells were pretreated with increasing concentrations of varenicline (1-3-10-30 $\mu \mathrm{M}) 24 \mathrm{~h}$ prior to the administration of predetermined LPS concentration $(4 \mu \mathrm{g} / \mathrm{ml})$. Varenicline suppressed LPS-elevated IL-1 $\beta$, IL-6, and TNFa levels (Figures $3 \mathrm{~A}-\mathrm{C})$. Higher concentrations of varenicline $(>1 \mu \mathrm{M})$ did not inhibit IL-6 and TNFa levels further. LPS-induced IL-1 $\beta$, IL-6, and TNFa elevations were also suppressed by dexamethasone to a similar extent as observed with varenicline (Figures $3 \mathbf{A}-\mathbf{C}$ ). Levels of these three parameters were not altered by varenicline or dexamethasone treatment per se (not shown).

\section{nAChR-Mediated Suppression of LPS-Induced IL-1 $\beta$, IL-, 6 and TNF $\alpha$ Levels by Varenicline}

RAW 264.7 cells were pretreated with mecamylamine (MEC) and/ or methyllycaconitine citrate (MLA) prior to incubation with varenicline $(1 \mu \mathrm{M})$ and LPS $(4 \mu \mathrm{g} / \mathrm{ml})$ for $24 \mathrm{~h}$. IL- $1 \beta$, IL- 6 , and TNFa levels significantly increased in MEC and MLA groups compared to varenicline-treated groups (Figures 4A-C). MEC or MLA did not alter IL-1 $\beta$, IL-6, and TNFa levels per se (not shown).

\section{Inhibitory Effects of Varenicline on LPS-Induced Cell Proliferation}

The cells were seeded and incubated in a biosafety cabinet for $30 \mathrm{~min}$ before the real-time proliferation assay. After $24 \mathrm{~h}$ of proliferation, the cells were treated with LPS $(4 \mu \mathrm{g} / \mathrm{ml})$ with or without varenicline $(1 \mu \mathrm{M})$ in the first set of experiments. In the second set, the cells were pretreated with MEC and MLA prior to varenicline $(1 \mu \mathrm{M})$ and LPS $(4 \mu \mathrm{g} / \mathrm{ml})$ administration. After drug treatment, changes in the cell proliferation rate (expressed as cell index, CI) were monitored for $24 \mathrm{~h}$ with 15 -min intervals.

The cell proliferation rate at $36^{\text {th }}$ and $48^{\text {th }}$ hours significantly increased in LPS groups (Figures $5 \mathbf{A}, \mathbf{B}$ ). The proliferation rate at $36^{\text {th }}$ and $48^{\text {th }}$ hours was not altered by varenicline significantly, indicating that varenicline has no cytotoxic effects at given concentrations (Figure 5A). Varenicline significantly decreased the LPS-induced cell proliferation rate at $36^{\text {th }}$ and $48^{\text {th }}$ hours (Figure 5B). However, MEC and MLA treatment did not antagonize the inhibitory effects of varenicline on LPS-induced proliferation (Figure 5B). MEC or MLA administration had no effect on the basal proliferation rate per se (not shown). 


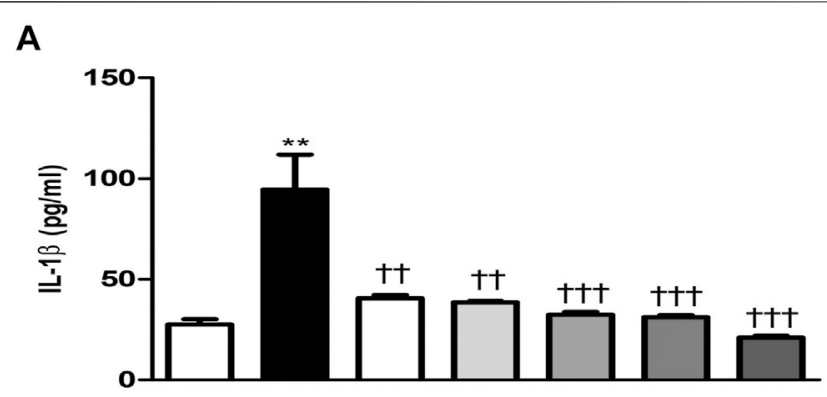

B

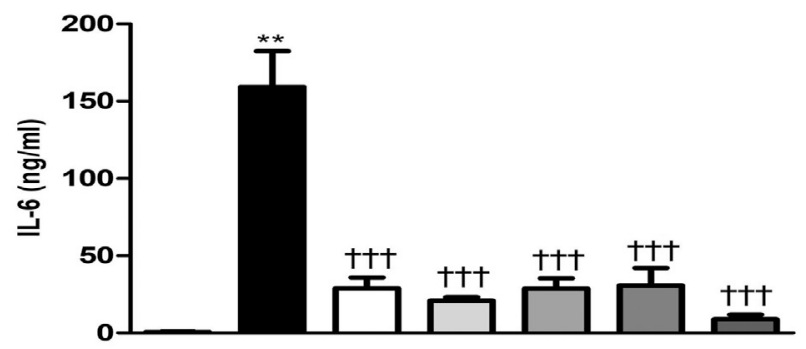

C

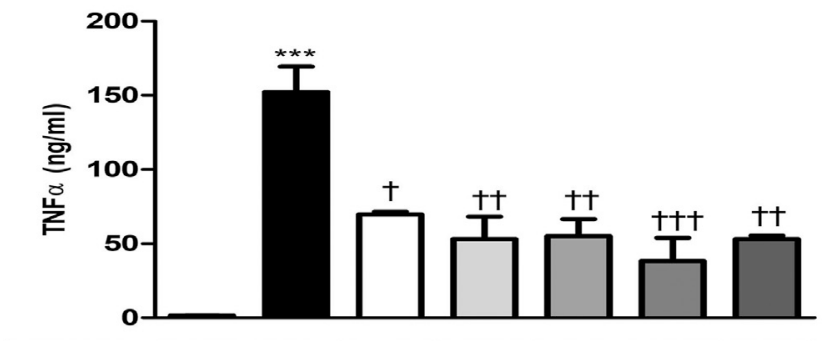

\begin{tabular}{|l|l|l|l|l|l|l|l|}
\hline $\operatorname{LPS}(4 \mu \mathrm{g} / \mathrm{ml})$ & & + & + & + & + & + & + \\
\hline $\operatorname{VAR}(1 \mu \mathrm{M})$ & & & + & & & & \\
\hline $\operatorname{VAR}(3 \mu \mathrm{M})$ & & & & + & & & \\
\hline $\operatorname{VAR}(10 \mu \mathrm{M})$ & & & & & + & & \\
\hline $\operatorname{VAR}(30 \mu \mathrm{M})$ & & & & & & + & \\
\hline $\operatorname{DEX}(0.1 \mu \mathrm{M})$ & & & & & & & + \\
\hline
\end{tabular}

FIGURE 3 | Effects of varenicline on LPS-induced IL-1 $\beta$, IL-6, and TNF $\alpha$ elevations via $\mathrm{AAChR}$. Shown are the effects of varenicline on $4 \mu \mathrm{g} / \mathrm{ml} \mathrm{LPS}$-induced IL-1 $\beta$ (A), IL-6 (B), and TNF $\alpha$ (C) levels and the comparison with dexamethasone. Data are expressed as mean \pm S.E.M. ${ }^{* \star}, p<0.01 ;{ }^{* \star *}, p<0.001$ vs. the control group; ${ }^{\dagger} p<0.05 ;{ }^{+\dagger} p<0.01,{ }^{+t} p<0.001$ vs. the LPS group, $n=5-7$, Oneway ANOVA with post hoc Tukey-Kramer multiple comparisons test or Student's $t$-test). VAR: varenicline, DEX: dexamethasone.

\section{Inhibitory Effects of Varenicline on LPS-Induced Cell Migration}

The cells were seeded for $30 \mathrm{~min}$ prior to the experiment and then pretreated with MEC and MLA prior to varenicline $(1 \mu \mathrm{M})$ and LPS $(4 \mu \mathrm{g} / \mathrm{ml})$ administration. After drug treatment, the change in the cell migration rate (expressed as cell index, CI) was monitored for $24 \mathrm{~h}$ at 15 -min intervals.

The cell migration rate significantly increased in LPS groups compared to control group at $12^{\text {th }}$ and $24^{\text {th }}$ hours $(p<0.01$,
Figure 6). Varenicline decreased LPS-induced cell migration comparable to LPS groups at $12^{\text {th }}$ and $24^{\text {th }}$ hours $(p<0.01$, Figure 6). Either MLA or MEC abolished varenicline's inhibitory effects on LPS-induced cell migration compared to vareniclinetreated groups at $12^{\text {th }}$ and $24^{\text {th }}$ hours $(p<0.01$, Figure 6$)$.

\section{DISCUSSION}

This study shows that varenicline significantly inhibits LPSinduced pro-inflammatory cytokine levels via $a 7 n A C h R$ along with concomitant cell proliferation and migration, suggesting its potential value in the prevention of inflammation by activating the cholinergic anti-inflammatory pathway. Currently used as a

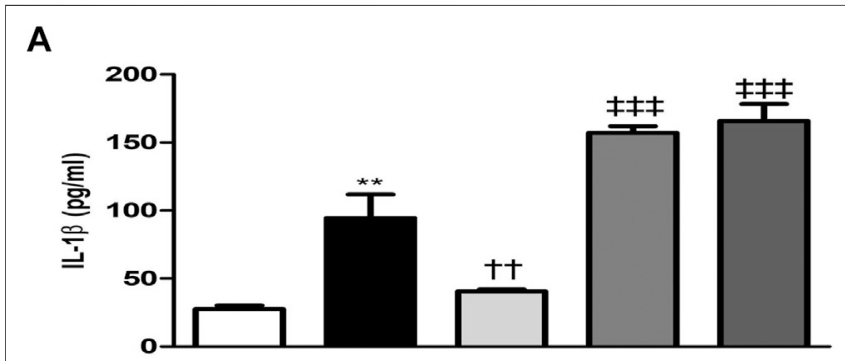

B

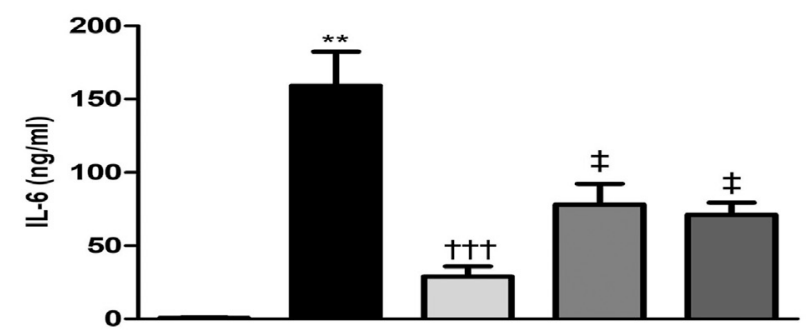

C

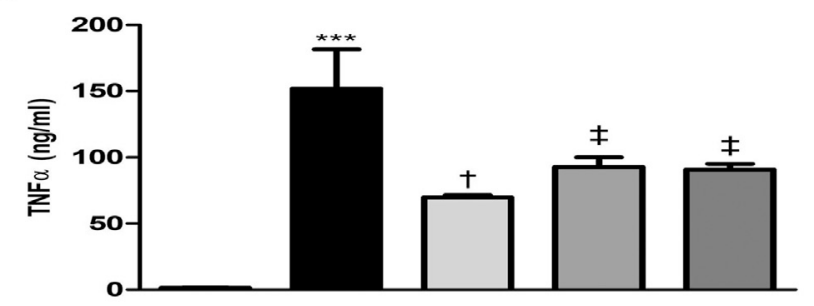

\begin{tabular}{|l|l|l|l|l|l|}
\hline $\operatorname{LPS}(4 \mu \mathrm{g} / \mathrm{ml})$ & & + & + & + & + \\
\hline $\operatorname{VAR}(1 \mu \mathrm{M})$ & & & + & + & + \\
\hline $\operatorname{MEC}(50 \mu \mathrm{M})$ & & & & + & \\
\hline MLA $(1 \mu \mathrm{M})$ & & & & & + \\
\hline
\end{tabular}

FIGURE 4 | Effects of varenicline on LPS-induced IL-1 $\beta$, IL-6, and TNF $\alpha$ elevations in the presence or absence of nAChR antagonists. Shown are $4 \mu \mathrm{g} /$ $\mathrm{ml}$ LPS-elevated IL-1 $\beta$ (A); IL-6 (B), and TNF $\alpha$ (C) levels in the absence or presence of varenicline $(\mathrm{VAR}, 1 \mu \mathrm{M})$, mecamylamine (MEC, $50 \mu \mathrm{M}$ ) and methyllycaconitine (MLA, $1 \mu \mathrm{M})$. Data are shown as mean \pm S.E.M. $\left({ }^{\star *} p<\right.$ $0.01 ;{ }^{* \star *} p<0.001$ vs. the control group, ${ }^{\dagger} p<0.05 ;{ }^{\dagger+} p<0.01,{ }^{+\dagger+} p<0.001$ vs. LPS group; ${ }^{\ddagger} p<0.05,{ }^{\neq \neq \neq} p<0.001$ vs. LPS + VAR, $n=5-7$, One-way ANOVA with post hoc Tukey-Kramer multiple comparisons test or Student's t-test). 

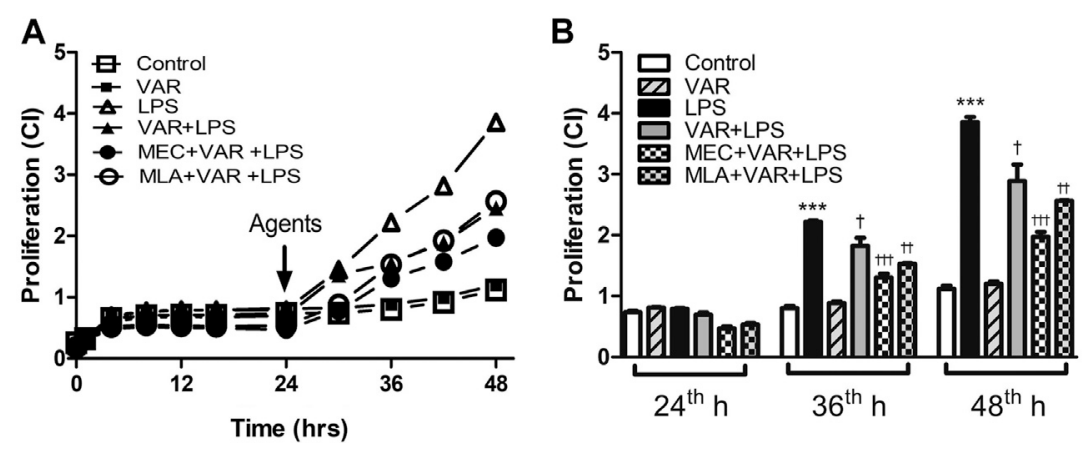

FIGURE $\mathbf{5}$ | Effects of varenicline on LPS-induced cell proliferation in the presence or absence of nAChR antagonists. Shown are line graphs drawn from the averaged data points of the real-time proliferation assay tracings $\mathbf{( A )}$ and the cumulative data (B). RAW 264.7 cells were treated with varenicline (VAR, $1 \mu \mathrm{M})$ in the presence or absence of mecamylamine (MEC, $50 \mu \mathrm{M})$ and methyllycaconitine (MLA, $1 \mu \mathrm{M})$ prior to lipopolysaccharide (LPS, $4 \mu \mathrm{g} / \mathrm{ml})$ administration at 24 th hour. Then, cell proliferation rates were monitored for $24 \mathrm{~h}$ after the treatments. Data are expressed as mean \pm S.E.M. $\left({ }^{\star \star \star} p<0.01\right.$ vs. the control group ${ }^{\dagger} p<0.05 ;{ }^{\dagger \dagger} p<0.01$, ${ }^{+t+} p<0.001$ vs. the LPS group, $n=5-7$, One-way ANOVA with post hoc Tukey-Kramer multiple comparisons test or Student's $t$-test). Cl: cell index.
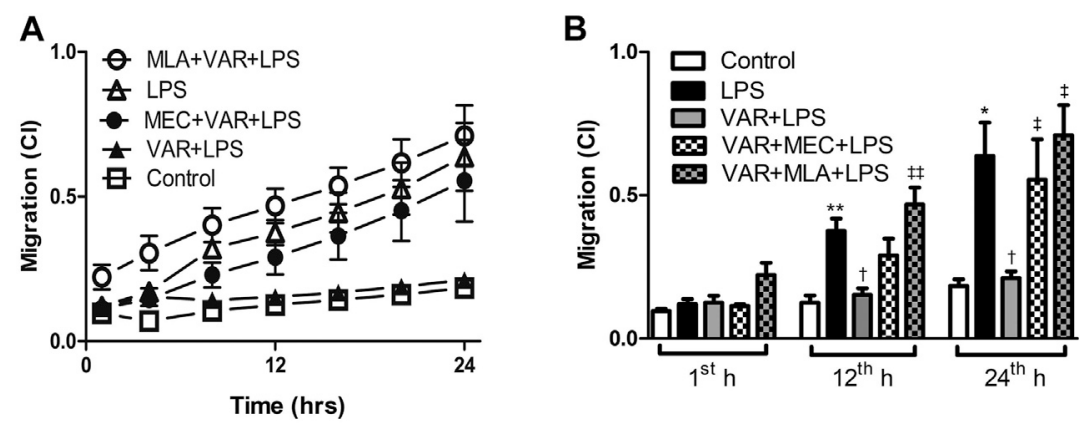

FIGURE 6 | Effects of varenicline on LPS-induced cell migration in the presence or absence of nAChR antagonists. Shown are line graphs drawn by the averaged data points of real-time migration assay tracings (A) and the cumulative data (B). RAW 264.7 cells were treated with varenicline (VAR, $1 \mu \mathrm{M})$ in the presence or absence of mecamylamine (MEC, $50 \mu \mathrm{M})$ and methyllycaconitine (MLA, $1 \mu \mathrm{M})$ prior to lipopolysaccharide (LPS, $4 \mu \mathrm{g} / \mathrm{ml})$ administration at the 24 th hour. Then, cell migration rates were monitored for $24 \mathrm{~h}$ after the treatments. Data are expressed as mean \pm S.E.M. $\left({ }^{\star} p<0.05 ;{ }^{* \star} p<0.01\right.$ vs. the control group; ${ }^{\dagger} p<0.05$ vs. the LPS group; ${ }^{\ddagger} p<$ $0.05,{ }^{\ddagger \ddagger} p<0.01$ vs. LPS + VAR group, $n=5-7$, One-way ANOVA with post hoc Tukey-Kramer multiple comparisons test or Student's $t$-test).

safe treatment option as a smoking cessation aid, varenicline has full agonistic properties on a7nAChRs (Mihalak et al., 2006a; Hays et al., 2008). A limited number of studies suggested a possible anti-inflammatory effectiveness of varenicline (Chen et al., 2017; Koga et al., 2018; McElroy et al., 2018). LPS is known to trigger inflammation by inducing the production of cytokines, including tumor necrosis factor (TNFa) and interleukins (Pavlov et al., 2003; Parrish et al., 2008; Yi et al., 2015). While moderately limiting local infections at the beginning, cytokines at higher levels lead to a widespread antiinflammatory response (i.e., cytokine storm). In this regard, the intracellular endosomes of mononuclear cells might need a secondary induction by ATP to release IL- $1 \beta$ further after LPS stimulation (Turola et al., 2012; Stoffels et al., 2015). Therefore, in the first part of this study, RAW 264.7 macrophages were treated with increasing concentrations of LPS to determine its optimal concentration $(4 \mu \mathrm{g} / \mathrm{ml})$ for inducing cytokine release, including IL- $1 \beta$.
Varenicline has also been shown to decrease inflammation in lung tissues of animals with emphysema (Koga et al., 2018) and to reduce brain inflammation in animals with stroke (Chen et al., 2017). A clinical study has also demonstrated that varenicline significantly decreased eicosanoid-related inflammation and oxidative damage in patients during smoking cessation therapy (McElroy et al., 2018). Consistent with these, our study showed that varenicline decreased LPS-induced inflammatory cytokine levels in RAW 264.7 macrophage cells. It is known that glucocorticoids are potent anti-inflammatory agents that modulate inflammation response through the attenuation of the cytokine release. Dexamethasone has been shown to decrease LPS-induced cytokine release in RAW 264.7 cells (Jeon et al., 2000; Ai et al., 2020). Our results showed no significant differences between varenicline and dexamethasone regarding the inhibition of IL- $1 \beta$, IL-6, and TNFa levels. In brief, regardless of the mechanism of action, the extension of varenicline's anti-inflammatory properties is similar to that of 
dexamethasone; however, its efficacy should also be confirmed in vivo.

Nicotinic receptors play important roles in the development of pain and inflammation associated with inflammatory pain models (Bagdas et al., 2015). The increase in cytokine levels in the presence of nAChR antagonists, MEC, and MLA, suggests the a7nAChR involvement in the anti-inflammatory effects of varenicline. Varenicline's anti-inflammatory effectiveness in lung and brain tissues in mice with emphysema and stroke has been shown to occur by a7nAChR activation (Chen et al., 2017; Koga et al., 2018). These studies provide indirect evidence for the antiinflammatory role of varenicline without investigating its effects on inflammatory cytokine levels. Accumulating evidence suggests that $\alpha 7 n A C h R s$ expressed on immune cells are required to balance the endogenous response to inflammation through the activation of the cholinergic system (Pavlov et al., 2003). Agents acting on $\alpha 7 n A C h R s$ have been shown to inhibit LPS-induced inflammatory response in various in vivo and in vitro studies (Pavlov et al., 2003; Wang et al., 2003; Yilmaz et al., 2006; Pavlov et al., 2007; Parrish et al., 2008; Yi et al., 2015; Koga et al., 2018). Several molecular mechanisms have been suggested for the a7nAChR-mediated inhibition of proinflammatory cytokines in macrophages, such as inhibiting the nuclear translocation of the transcription factor NF- $\mathrm{BB}$ and JAK2/ STAT3 signaling pathway. As found among ligand-gated $\mathrm{Ca}^{2+}$ channels, the activation of a7nAChRs leads to the phosphorylation of AKT by JAK2 and PI3K upon calcium influx (Tsurutani et al., 2005; Chatterjee et al., 2009; Marrero and Bencherif, 2009) Our data provide experimental evidence that the $a 7 \mathrm{nAChR}$ agonist varenicline suppresses inflammatory cytokine release through a receptordependent mechanism and may have a therapeutic potential as an agent acting on the cholinergic anti-inflammatory pathway, although its downstream intracellular mechanisms were not investigated in the present study. Anti-inflammatory effects of varenicline may also be potentiated by decreases in LPS-elevated macrophage inflammatory proteins (MIP-1 $\alpha$, the MIP-1 $\beta$, and MIP-2) (present study) which cause IL-1, IL-6, and TNFa release from macrophages besides their chemotactic properties (Bird and Kirstein, 2009; Selli et al., 2016).

The basal proliferation rate unaltered by varenicline may also indicate that the drug is not cytotoxic at effective concentrations. Additionally, varenicline treatment decreased LPS-induced cell proliferation, without any $\mathrm{nAChR}$ involvement. Studies suggest that the $\alpha 7 \mathrm{nAChR}$ expression was associated with an increase in cell proliferation in breast, gastric, and lung cancer epithelial cells (Dang et al., 2016). Another study showed that $\alpha 7 \mathrm{nAChR}$ agonist GTS-21 only partially decreased LPS-induced macrophage cell proliferation at early LPS response (Khan et al., 2012). These evidences suggest that nicotinic receptors may only play a partial role in LPS-induced macrophage proliferation. During inflammation, macrophage proliferation and differentiation are mediated by the LPSelevated levels of granulocyte colony-stimulating factor (G-CSF) and granulocyte macrophage CSF (GM-CSF) (Li et al., 2014; Lee et al., 2017). Cytokine array showed that the suppression of LPS-induced G-CSF and GM-CSF levels by varenicline treatment might be involved in slowing the proliferation rate of RAW 264.7 cells (the present study).

LPS-induced TNF $\alpha$, IL-1 $\beta$, and IL- 6 facilitate macrophage migration (Bozza et al., 1999; Toh et al., 2006; Yang et al.,
2015). Acetylcholine has been shown to inhibit LPS-induced matrix metalloproteinase 9 (MMP-9) production and macrophage migration through $\alpha 7 \mathrm{nAChR}$ activation (Yang et al., 2015). Similarly, $a 7 \mathrm{nAChRs}$ were found to be operational in LPS-induced macrophage migration, along with decrease in cytokine levels at non-cytotoxic varenicline concentrations. Our cytokine array data suggest that varenicline's antimigratory effects may also depend on the decreased levels of RANTES, macrophage inflammatory proteins (MIP- $1 \alpha$, and MIP-1 $\beta$ and MIP-2), interferon-gamma inducible protein of $10 \mathrm{kDa}$ (IP-10), and monocyte chemoattractant protein (MCP-1 or JE) (Lee et al., 1990; Nakata et al., 1991; Byrnes et al., 1999; Arima et al., 2000; Tajima et al., 2008). In addition to their chemotactic properties, MIPs have pro-inflammatory effects that induce IL1, IL-6, and TNFa release from macrophages (Mühl and Dinarello, 1997; Haberstroh et al., 2002; Tsurutani et al., 2005; Deshmane et al., 2009; Marrero and Bencherif, 2009; Bandow et al., 2012), also confirmed by the present study as varenicline treatment decreased MIP-1 $\alpha$, MIP- $1 \beta$, and MIP-2 levels, along with other cytokines.

\section{LIMITATIONS}

Investigating the intracellular mechanism of varenicline on inflammatory response was beyond the scope of the present study. Although apparently relevant at the pre-clinical level, in vivo studies should be performed to confirm varenicline's inhibitory effects on LPS-induced cytokine release via $a 7 \mathrm{nAChR}$ activation.

\section{CONCLUSION}

Inflammation is a complicated process that requires specific and diverse treatment strategies. This study originally demonstrates in a model of LPS-induced inflammation using murine macrophage cell lines that varenicline stimulates the cholinergic anti-inflammatory pathway through $\alpha 7 \mathrm{nAChRs}$, resulting in the inhibition of cell migration and reduction of inflammatory cytokine secretion. Clarification of the underlying mechanism of action in different experimental models including the inflammatory state may contribute to the validation of varenicline's efficacy for repurposing as an anti-inflammatory agent.

\section{DATA AVAILABILITY STATEMENT}

The raw data supporting the conclusions of this article will be made available by the authors, without undue reservation.

\section{AUTHOR CONTRIBUTIONS}

EB and MT contributed to the conceptualization, methodology, investigation, data analysis, writing the original article, reviewing, editing, and visualization. HE contributed to the investigation, 
data analysis, reviewing, and editing. MA and MG contributed to the reviewing and editing.

\section{FUNDING}

This study was financially supported by the Scientific and Technological Research Council of Turkey (TUBITAK 119 S936 to MT).

\section{REFERENCES}

Ai, F., Zhao, G., Lv, W., Liu, B., and Lin, J. (2020). Dexamethasone Induces Aberrant Macrophage Immune Function and Apoptosis. Oncol. Rep. 43, 427-436. doi:10.3892/or.2019.7434

Arima, K., Nasu, K., Narahara, H., Fujisawa, K., Matsui, N., and Miyakawa, I. (2000). Effects of Lipopolysaccharide and Cytokines on Production of RANTES by Cultured Human Endometrial Stromal Cells. Mol. Hum. Reprod. 6, 246-251. doi:10.1093/molehr/6.3.246

Bagdas, D., AlSharari, S. D., Freitas, K., Tracy, M., and Damaj, M. I. (2015). The Role of Alpha5 Nicotinic Acetylcholine Receptors in Mouse Models of Chronic Inflammatory and Neuropathic Pain. Biochem. Pharmacol. 97, 590-600. doi:10.1016/j.bcp.2015.04.013

Bandow, K., Kusuyama, J., Shamoto, M., Kakimoto, K., Ohnishi, T., and Matsuguchi, T. (2012). LPS-induced Chemokine Expression in Both MyD88-dependent and -independent Manners Is Regulated by Cot/Tpl2ERK axis in Macrophages. FEBS Lett. 586, 1540-1546. doi:10.1016/ j.febslet.2012.04.018

Bernik, T. R., Friedman, S. G., Ochani, M., DiRaimo, R., Ulloa, L., Yang, H., et al. (2002). Pharmacological Stimulation of the Cholinergic Antiinflammatory Pathway. J. Exp. Med. 195, 781-788. doi:10.1084/jem.20011714

Bird, C., and Kirstein, S. (2009). Real-time, Label-free Monitoring of Cellular Invasion and Migration with the xCELLigence System. Nat. Methods 6, v-vi. doi:10.1038/nmeth.f.263

Borovikova, L. V., Ivanova, S., Zhang, M., Yang, H., Botchkina, G. I., Watkins, L. R., et al. (2000). Vagus Nerve Stimulation Attenuates the Systemic Inflammatory Response to Endotoxin. Nature 405, 458-462. doi:10.1038/35013070

Bozza, M., Satoskar, A. R., Lin, G., Lu, B., Humbles, A. A., Gerard, C., et al. (1999). Targeted Disruption of Migration Inhibitory Factor Gene Reveals its Critical Role in Sepsis. J. Exp. Med. 189, 341-346. doi:10.1084/jem.189.2.341

Byrnes, H. D., Kaminski, H., Mirza, A., Deno, G., Lundell, D., and Fine, J. S. (1999). Macrophage Inflammatory Protein-3 Beta Enhances IL-10 Production by Activated Human Peripheral Blood Monocytes and T Cells. J. Immunol. 163, 4715-4720.

Cano, P. M., Vargas, A., and Lavoie, J.-P. (2016). A Real-Time Assay for Neutrophil Chemotaxis. Biotechniques 60, 245-251. doi:10.2144/000114416

Chatterjee, P. K., Al-Abed, Y., Sherry, B., and Metz, C. N. (2009). Cholinergic Agonists Regulate JAK2/STAT3 Signaling to Suppress Endothelial Cell Activation. Am. J. Physiology-Cell Physiol. 297, C1294-C1306. doi:10.1152/ ajpcell.00160.2009

Chen, S., Bennet, L., and McGregor, A. L. (2017). Delayed Varenicline Administration Reduces Inflammation and Improves Forelimb Use Following Experimental Stroke. J. Stroke Cerebrovasc. Dis. 26, 2778-2787. doi:10.1016/j.jstrokecerebrovasdis.2017.06.051

Dang, N., Meng, X., and Song, H. (2016). Nicotinic Acetylcholine Receptors and Cancer. Biomed. Rep. 4, 515-518. doi:10.3892/br.2016.625

De Jonge, W. J., and Ulloa, L. (2007). The Alpha7 Nicotinic Acetylcholine Receptor as a Pharmacological Target for Inflammation. Br. J. Pharmacol. 151, 915-929. doi:10.1038/sj.bjp.0707264

Deshmane, S. L., Kremlev, S., Amini, S., and Sawaya, B. E. (2009). Monocyte Chemoattractant Protein-1 (MCP-1): An Overview. J. Interferon Cytokine Res. 29, 313-326. doi:10.1089/jir.2008.0027

Fujii, T., Mashimo, M., Moriwaki, Y., Misawa, H., Ono, S., Horiguchi, K., et al. (2017). Expression and Function of the Cholinergic System in Immune Cells. Front. Immunol. 8, 1085. doi:10.3389/fimmu.2017.01085

\section{ACKNOWLEDGMENTS}

The authors would like to thank Dr. Sermin Genc (Izmir Biomedicine and Genome Institute) and Elips Company (Istanbul) for generously providing RAW264.7 cells and RTCA platform, respectively. The text has been checked and proofread by Simon Mumford (Izmir University of Economics).

Haberstroh, U., Pocock, J., Gómez-Guerrero, C., Helmchen, U., Hamann, A., Gutierrez-Ramos, J. C., et al. (2002). Expression of the Chemokines MCP-1/ CCL2 and RANTES/CCL5 Is Differentially Regulated by Infiltrating Inflammatory Cells. Kidney Int. 62, 1264-1276. doi:10.1111/j.15231755.2002.kid572.x

Hays, J. T., Ebbert, J. O., and Sood, A. (2008). Efficacy and Safety of Varenicline for Smoking Cessation. Am. J. Med. 121, S32-S42. doi:10.1016/ j.amjmed.2008.01.017

Jeon, Y. J., Han, S. H., Lee, Y. W., Lee, M., Yang, K. H., and Kim, H. M. (2000). Dexamethasone Inhibits IL-1 $\beta$ Gene Expression in LPS-Stimulated RAW 264.7 Cells by Blocking NF- $\kappa \mathrm{B} /$ Rel and AP-1 Activation. Immunopharmacology 48, 173-183. doi:10.1016/S0162-3109(00)00199-5

Khan, M. A. S., Farkhondeh, M., Crombie, J., Jacobson, L., Kaneki, M., and Martyn, J. A. J. (2012). Lipopolysaccharide Upregulates a7 Acetylcholine Receptors. Shock 38, 213-219. doi:10.1097/SHK.0b013e31825d628c

Koga, M., Kanaoka, Y., Tashiro, T., Hashidume, N., Kataoka, Y., and Yamauchi, A. (2018). Varenicline Is a Smoking Cessation Drug that Blocks Alveolar Expansion in Mice Intratracheally Administrated Porcine Pancreatic Elastase. J. Pharmacol. Sci. 137, 224-229. doi:10.1016/j.jphs.2018.06.007

Lee, J.-H., Kim, B., Jin, W. J., Kim, H.-H., Ha, H., and Lee, Z. H. (2017). Pathogenic Roles of CXCL10 Signaling through CXCR3 and TLR4 in Macrophages and T Cells: Relevance for Arthritis. Arthritis Res. Ther. 19, 163. doi:10.1186/ s13075-017-1353-6

Lee, M.-T., Kaushansky, K., Ralph, P., and Ladner, M. B. (1990). Differential Expression of M-CSF, G-CSF, and GM-CSF by Human Monocytes. J. Leukoc. Biol. 47, 275-282. doi:10.1002/jlb.47.3.275

Li, W., Yang, S., Kim, S. O., Reid, G., Challis, J. R. G., and Bocking, A. D. (2014). Lipopolysaccharide-induced Profiles of Cytokine, Chemokine, and Growth Factors Produced by Human Decidual Cells Are Altered by Lactobacillus Rhamnosus Gr-1 Supernatant. Reprod. Sci. 21, 939-947. doi:10.1177/ 1933719113519171

Marrero, M. B., and Bencherif, M. (2009). Convergence of Alpha 7 Nicotinic Acetylcholine Receptor-Activated Pathways for Anti-apoptosis and Antiinflammation: Central Role for JAK2 Activation of STAT3 and NF-Kb. Brain Res. 1256, 1-7. doi:10.1016/j.brainres.2008.11.053

McElroy, J. P., Carmella, S. G., Heskin, A. K., Tang, M. K., Murphy, S. E., Reisinger S. A., et al. (2018). Effects of Cessation of Cigarette Smoking on Eicosanoid Biomarkers of Inflammation and Oxidative Damage. PLoS One 14, e0218386-12. doi:10.1371/journal.pone.0218386

Mihalak, K. B., Carroll, F. I., Luetje, C. W., Mihalak, K. B., Carroll, F. I., and Luetje, W. (2006). Varenicline Is a Partial Agonist at $\alpha 4 \beta 2$ and a Full Agonist at $\alpha 7$ Neuronal Nicotinic Receptors. Mol. Pharmacol. 70 (3), 801-805. doi:10.1124/ mol.106.025130.therapies

Mihalak, K. B., Carroll, F. I., and Luetje, C. W. (2006). Varenicline Is a Partial Agonist at $\alpha 4 \beta 2$ and a Full Agonist at $\alpha 7$ Neuronal Nicotinic Receptors. Mol. Pharmacol. 70, 801-805. doi:10.1124/mol.106.025130

Mühl, H., and Dinarello, C. A. (1997). Macrophage Inflammatory Protein-1 Alpha Production in Lipopolysaccharide-Stimulated Human Adherent Blood Mononuclear Cells Is Inhibited by the Nitric Oxide Synthase Inhibitor $\mathrm{N}(\mathrm{G})$-monomethyl-L-arginine. J. Immunol. 159, 5063-5069.

Murdock, J. L., and Núñez, G. (2016). TLR4: The Winding Road to the Discovery of the LPS Receptor. J.I. 197, 2561-2562. doi:10.4049/jimmunol.1601400

Nakata, K., Akagawa, K. S., Fukayama, M., Hayashi, Y., Kadokura, M., and Tokunaga, T. (1991). Granulocyte-macrophage colony-stimulating Factor Promotes the Proliferation of Human Alveolar Macrophages In Vitro. J. Immunol. 147, 1266-1272. 
Palsson-McDermott, E. M., and O'Neill, L. A. J. (2004). Signal Transduction by the Lipopolysaccharide Receptor, Toll-like Receptor-4. Immunology 113, 153-162. doi:10.1111/j.1365-2567.2004.01976.x

Parrish, W. R., Rosas-Ballina, M., Gallowitsch-Puerta, M., Ochani, M., Ochani, K., Yang, L.-H., et al. (2008). Modulation of TNF Release by Choline Requires a 7 Subunit Nicotinic Acetylcholine Receptor-Mediated Signaling. Mol. Med. 14, 567-574. doi:10.2119/2008-00079.Parrish

Pavlov, V. A., Ochani, M., Yang, L.-H., Gallowitsch-Puerta, M., Ochani, K., Lin, X., et al. (2007). Selective a7-nicotinic Acetylcholine Receptor Agonist GTS-21 Improves Survival in Murine Endotoxemia and Severe Sepsis*. Crit. Care Med. 35, 1139-1144. doi:10.1097/01.CCM.0000259381.56526.96

Pavlov, V. A., Wang, H., Czura, C. J., Friedman, S. G., and Tracey, K. J. (2003). The Cholinergic Anti-inflammatory Pathway: a Missing Link in Neuroimmunomodulation. Mol. Med. 9, 125-134. doi:10.1007/bf03402177

Pinder, N., Bruckner, T., Lehmann, M., Motsch, J., Brenner, T., Larmann, J., et al. (2019). Effect of Physostigmine on Recovery from Septic Shock Following Intra-abdominal Infection - Results from a Randomized, Double-Blind, Placebo-Controlled, Monocentric Pilot Trial (Anticholium Per Se). J. Crit. Care 52, 126-135. doi:10.1016/j.jcrc.2019.04.012

Pinder, N., Zimmermann, J. B., Gastine, S., Würthwein, G., Hempel, G., Bruckner, T., et al. (2019). Continuous Infusion of Physostigmine in Patients with Perioperative Septic Shock: A Pharmacokinetic/pharmacodynamic Study with Population Pharmacokinetic Modeling. Biomed. Pharmacother. 118, 109318. doi:10.1016/j.biopha.2019.109318

Selli, C., Erac, Y., and Tosun, M. (2016). Effects of Cell Seeding Density on RealTime Monitoring of Anti-proliferative Effects of Transient Gene Silencing. J. Biol. Res-thessaloniki 23, 1-8. doi:10.1186/s40709-016-0057-4

Snider, S. A., Margison, K. D., Ghorbani, P., LeBlond, N. D., O’Dwyer, C., Nunes, J. R. C., et al. (2018). Choline Transport Links Macrophage Phospholipid Metabolism and Inflammation. J. Biol. Chem. 293, 11600-11611. doi:10.1074/ jbc.RA118.003180

Stoffels, M., Zaal, R., Kok, N., van der Meer, J. W. M., Dinarello, C. A., and Simon, A. (2015). ATP-induced IL-1 $\hat{\mathrm{I}}^{2}$ Specific Secretion: True under Stringent Conditions. Front. Immunol. 6, 54. doi:10.3389/fimmu.2015.00054

Tajima, T., Murata, T., Aritake, K., Urade, Y., Hirai, H., Nakamura, M., et al. (2008). Lipopolysaccharide Induces Macrophage Migration via Prostaglandin D2and Prostaglandin E2. J. Pharmacol. Exp. Ther. 326, 493-501. doi:10.1124/jpet.108.137992

Toh, M.-L., Aeberli, D., Lacey, D., Yang, Y., Santos, L. L., Clarkson, M., et al. (2006). Regulation of IL-1 and TNF Receptor Expression and Function by Endogenous Macrophage Migration Inhibitory Factor. J. Immunol. 177, 4818-4825. doi:10.4049/jimmunol.177.7.4818

Tsurutani, J., Castillo, S. S., Brognard, J., Granville, C. A., Zhang, C., Gills, J. J., et al. (2005). Tobacco Components Stimulate Akt-dependent Proliferation and
NFkB-dependent Survival in Lung Cancer Cells. Carcinogenesis 26, 1182-1195. doi:10.1093/carcin/bgi072

Turola, E., Furlan, R., Bianco, F., Matteoli, M., and Verderio, C. (2012). Microglial Microvesicle Secretion and Intercellular Signaling. Front. Physio. 3, 149. doi:10.3389/fphys.2012.00149

Wang, H., Yu, M., Ochani, M., Amella, C. A., Tanovic, M., Susarla, S., et al. (2003). Nicotinic Acetylcholine Receptor a7 Subunit Is an Essential Regulator of Inflammation. Nature 421, 384-388. doi:10.1038/nature01339

Yang, Y.-H., Li, D.-L., Bi, X.-Y., Sun, L., Yu, X.-J., Fang, H.-L., et al. (2015). Acetylcholine Inhibits LPS-Induced MMP-9 Production and Cell Migration via the A7 nAChR-Jak2/stat3 Pathway in RAW264.7 Cells. Cell. Physiol. Biochem. 36, 2025-2038. doi:10.1159/000430170

Yi, L., Luo, J.-f., Xie, B.-b., Liu, J.-x., Wang, J.-y., Liu, L., et al. (2015). a7 Nicotinic Acetylcholine Receptor Is a Novel Mediator of Sinomenine Anti-inflammation Effect in Macrophages Stimulated by Lipopolysaccharide. Shock 44, 188-195. doi:10.1097/SHK.0000000000000389

Yilmaz, Z., Ilcol, Y. O., Torun, S., and Ulus, I. H. (2006). Intravenous Administration of Choline or CDP-Choline Improves Platelet Count and Platelet Closure Times in Endotoxin-Treated Dogs. Shock 25, 73-79. doi:10.1097/01.shk.0000185796.04589.15

Zimmermann, J. B., Pinder, N., Bruckner, T., Lehmann, M., Motsch, J., Brenner, T., et al. (2017). Adjunctive Use of Physostigmine Salicylate (Anticholium) in Perioperative Sepsis and Septic Shock: Study Protocol for a Randomized, Double-Blind, Placebo-Controlled, Monocentric Trial (Anticholium Per Se). Trials 18, 1-10. doi:10.1186/s13063-017-2231-x

Conflict of Interest: The authors declare that the research was conducted in the absence of any commercial or financial relationships that could be construed as a potential conflict of interest.

Publisher's Note: All claims expressed in this article are solely those of the authors and do not necessarily represent those of their affiliated organizations, or those of the publisher, the editors, and the reviewers. Any product that may be evaluated in this article, or claim that may be made by its manufacturer, is not guaranteed or endorsed by the publisher.

Copyright (c) 2021 Baris, Efe, Gumustekin, Arici and Tosun. This is an open-access article distributed under the terms of the Creative Commons Attribution License (CC $B Y)$. The use, distribution or reproduction in other forums is permitted, provided the original author(s) and the copyright owner(s) are credited and that the original publication in this journal is cited, in accordance with accepted academic practice. No use, distribution or reproduction is permitted which does not comply with these terms. 